\title{
Hepatite A
}

\author{
Hepatitis A
}

Fausto E.L. Pereira ${ }^{1}$ e Carlos S. Gonçalves ${ }^{1}$

\begin{abstract}
Resumo $A$ hepatite $A$ é conhecida desde as antigas civilizações chinesa, grega e romana, mas o primeiro relato escrito se deu no século 18. O agente é um picornavírus, do genêro Hepatovírus e o RNA viral possui fita simples. Existem sete genótipos. Nas infecções naturais, os anticorpos das classes IgM e IgA são os mais precoces, aparecendo junto com as primeiras manifestações clínicas, mas podem surgir apenas no final da primeira semana de doença. A infecção pelo vírus da hepatite A resulta em infecção assintomática, infecção sintomática anictérica, ou em infecção sintomática ictérica. A forma fulminante da hepatite não é freqüente. $O$ diagnóstico etiológico é feito pela pesquisa dos anticorpos anti-VHA da classe IgM, geralmente, pelo método de ELISA. Nenhum medicamento, exceto os sintomáticos, devem ser prescritos. A imunoprofilaxia passiva é feita pela injeção intramuscular de gamaglobulina anti-A e a imunoprofilaxia ativa através da vacinação.
\end{abstract}

Palavras-chaves: Hepatite A. Icterícia. Hepatite fulminante. Vacina.

Abstract Hepatitis A infection is known since the ancient Chinese, Greek and Roman civilizations but the first documented report was published in the eighteenth century. The hepatovirus belongs to the Picornaviridae family, and carries a single strand RNA. There are 7 genotypes. Antibodies of the lgM and lgA classes, during natural infections, appear early in the serum, together with the first clinical manifestations of the disease, but they may also appear at the end of the first week of infection. There is a spectrum of clinical presentation: asymptomatic infection, symptomatic without jaundice and symptomatic jaundiced. A rare fatal form of hepatitis has been described. Diagnosis of the hepatitis A infection is confirmed by the finding of IgM anti-HAV antibodies, routinely performed using an ELISA test. Treatment is supportive. Intramuscular anti-A gamma globulin is used for passive immune prophylaxis, and there is an efficient vaccine for active immune prophylaxis.

Key-words: Hepatitis A. Jaundice. Fulminant hepatitis. Vaccine.

A hepatite A é conhecida desde as antigas civilizações chinesa, grega e romana, mas o primeiro relato escrito, segundo revisão feita por Cockayne $(1912)^{12}$, foi a descrição de uma epidemia na ilha de Minorca no século 18 (Epidemic Diseases of Minorca, 1744 to1749). A seguir, muitos outros relatos de epidemias foram feitos, e a denominação de icterícia catarral foi dada por Virchow ${ }^{69}$, devido à quantidade de trombos biliares observados nas necropsias, admitindo o autor que a obstrução biliar era a causa da doença (icterícia). Essa denominação foi utilizada até a década de 40. Em 1908 e 1912, McDonalds ${ }^{47}$ e Cockayne ${ }^{12}$, respectivamente, utilizaram a palavra vírus para se referir à etiologia da icterícia catarral; no entanto a palavra foi usada no seu sentido genérico, de um agente lesivo, tendo sido utilizada inclusive a expressão "agente virulento". Uma suspeita mais justificada da etiologia virótica da doença só foi feita em 1931 por Findlay e cols $^{20}$, que, em relato a Royal Society of Tropical Medicine and Hygiene, discorrem sobre a história da doença e de uma epidemia recente, admitindo que era causada por um vírus, agente ultramicroscópico, que só infecta o homem. O fato interessante nessa época foi o aparecimento da doença em um dos autores, menos de cinco semanas depois de haver manipulado o soro de pacientes com icterícia catarral, tendo sido essa a primeira evidencia de transmissão da doença através do soro de pacientes nas fases iniciais da infecção.

A transmissão da doença do homem ao homem foi demonstrada em voluntários na Alemanha em $1942^{82}$, no Oriente Médio em $1943^{9}$ e nos Estados Unidos da América em $1944^{27} 45$. Esses experimentos

\footnotetext{
1. Núcleo de Doenças Infecciosas e Departamento de Clínica Médica do Centro Biomédico da Universidade Federal do Espírito Santo, Vitória, ES. Endereço para correspondência: Dr. Fausto E.L. Pereira. Núcleo de Doenças Infecciosas/UFES. Avenida Marechal Campos 1468, $29040-091$ Vitória, ES, Brasil. e-mail:felp@ndi.ufes.br

Recebido para publicação em 25/4/2003

Aceito em 28/5/2003
} 
estabeleceram o período de incubação da doença e demonstraram que ela era transmitida pela ingestão de fezes e, excepcionalmente de soro, se esse fosse originado de um indivíduo nos primeiros dias da doença. Foi em humanos que o grupo da Universidade de Yale não só confirmou a transmissão fecal-oral, como também observou que a inoculação de soro era capaz de produzir icterícia com período de incubação muito maior do que o da icterícia catarral. Esse grupo estabeleceu com clareza a existência de duas formas de hepatite, uma, a hepatite infecciosa e outra, a ictericia sérica ou hepatite a soro homólogo, com períodos de incubação bem distintos e modo de transmissão diferente ${ }^{54}$. Nessa época propuseram a utilização do nome hepatite A para a hepatite infecciosa e hepatite B para a icterícia sérica. Tinham idéia clara da etiologia viral, mas não estavam seguros se o vírus era o mesmo ou se havia diferentes vírus. A expressão icterícia catarral foi definitivamente abandonada após as observações em humanos, realizados em uma escola de excepcionais em State Island, NY. Nesses estudos, se confirmaram as observações anteriores e se demonstrou a utilidade da dosagem da transaminase glutâmico-oxalacética para identificar a hepatite infecciosa em pacientes oligossintomáticos e anictéricos ${ }^{39} 40$. Foi no estudo de um surto de casos na vizinhança da escola que obtiveram duas misturas de soros padrão, MS-1 que transmitia a hepatite A e MS-2 que transmitia a hepatite B. Foi o MS1 que possibilitou a obtenção do primeiro modelo experimental, após sua inoculação em saguis ${ }^{31}$ A partir dos saguis infectados se conseguiu, pela primeira vez, através da imunomicroscopia-eletrônica, demonstrar partículas virais nas fezes de pacientes nas fases iniciais da hepatite A. A Tabela 1 resume alguns dados sobre a evolução histórica dos conhecimentos básicos sobre a hepatite A.

Tabela 1- Resumo de alguns dados históricos sobre a evolução dos conhecimentos sobre a hepatite A.

\begin{tabular}{|c|c|c|}
\hline Ano & Autor & Evento \\
\hline 1745 & Cleghorn, citado em Cockayne $^{12}$ & $\begin{array}{l}\text { Primeiro relato escrito } \\
\text { Epidemic Diseases of Minorca, } 1744 \text { to } 1749\end{array}$ \\
\hline 1865 & Virchow citado na ref 17 & Introdução do nome icterícia catarral \\
\hline 1908 & S McDonalds $^{47}$ & Utilizaram a palavra vírus ao se referir a doença, mas com a conotação de agente lesivo \\
\hline 1912 & EA Cockayne $^{12}$ & Primeira descrição sistematizada da doença \\
\hline 1931 & GM Findley, JL Dunlop, $\mathrm{HC}$ Brown ${ }^{20}$ & Proposição mais sugestiva da etiologia viral \\
\hline 1939 & P Iversen \& K Roholm ${ }^{33}$ & Primeiras descrição de lesões em biópsias hepáticas de pacientes com icterícia catarral \\
\hline 1943 & JH Dible, J McMichael \& SPV Sherlock ${ }^{15}$ & esporádica benigna . \\
\hline 1947 & TB Mallory ${ }^{46}$ & Ausência de diferenças nas lesões em hepatite epidêmica (A) e icterícia sérica (B) \\
\hline 1942 & H Voegt (Alemanha) ${ }^{82}$ & Primeiros experimentos de transmissão homem a homem da doença. \\
\hline 1943 & J D Cameron (Oriente Médio) ${ }^{9}$ & \\
\hline 1944 & WP Havens et al (Univ Yale, USA) ${ }^{21}$ & \\
\hline \multirow[t]{3}{*}{1945} & J Stokes Jr \& JR Neefe ${ }^{73}$ & Primeiros estudos de proteção de hepatite A usando soro imune em epidemias. \\
\hline & SS Gellis et $\mathrm{al}^{24}$ & Soro proteção em inoculação experimental \\
\hline & WP Havens et $\mathrm{al}^{29}$ & \\
\hline 1946 & JR Paul et al (Univ Yale, USA) & Separação da icterícia catarral em hepatite infecciosa e hepatite sérica \\
\hline 1947 & $\begin{array}{l}\text { Comentário anônimo } \\
\text { do Lancet citando Mac Callum }{ }^{16}\end{array}$ & Proposta de separação das hepatites em hepatite A e hepatite B \\
\hline 1959 & SR Krugman et al ${ }^{40}$ & Estudo na Willowbrook State School,State Island, NY, em excepcionais. Confirmam a \\
\hline 1962 & SR Krugman et al ${ }^{39}$ & $\begin{array}{l}\text { transmisão feco-oral e sérica das hepatites A e B. Usam a TGO para identificar formas } \\
\text { anictéricas }\end{array}$ \\
\hline 1969 & AW Holmes et al ${ }^{31}$ & Primeira inoculação da amostra MS-1 em saguis. \\
\hline 1973 & SM Feinstone et $\mathrm{al}^{18}$ & O VHA é detectado por imuno-microscopia-eletrônica em fezes de prisioneiros infectados \\
\hline 1975 & $\begin{array}{l}\text { JJ Provost et } \mathrm{al}^{58} \\
\text { Miller et al } \\
\text { RH Purcell et } \mathrm{al}^{60}\end{array}$ & $\begin{array}{l}\text { Teste de fixação de complemento } \\
\text { Teste de imunocito-aderência } \\
\text { Rádioimunoensaio (RIA) }\end{array}$ \\
\hline 1979 & DW Bradley et al ${ }^{8}$ & $\begin{array}{l}\text { RIA de ligação competitiva. Avaliação da IgM anti-A. } \\
\text { ELISA por competiçao para detectar IgM anti-VHA }\end{array}$ \\
\hline 1991 & $\begin{array}{l}\text { MH Sjogren et } \mathrm{al}^{70} \\
\mathrm{~K} \text { Midthun et } \mathrm{al}^{49}\end{array}$ & $\begin{array}{l}\text { Primeiros resultados de uma vacina com o vírus A inativado (com formol) e com o vírus } \\
\text { atenuado }\end{array}$ \\
\hline 1992 & $\begin{array}{l}\text { Smith-Kline Beecham } \\
\text { Merck Sharpe Dohme }\end{array}$ & $\begin{array}{l}\text { Vacinas disponíveis no comércio, com vírus atenuado (licenciadas a partir de } 1995 \text { pelo FDA } \\
\text { nos EE UU). }\end{array}$ \\
\hline
\end{tabular}

\section{O VÍRUS DA HEPATITE A}

$\mathrm{O}$ vírus $\mathrm{A}$ da hepatite (VHA) é um Picornaviridae, do genero Hepatovirus. O RNA viral é de fita simples, com sentido positivo, portanto, pronto para a tradução. O RNA genômico está associado covalentemente à proteína VPg na extremidade $5^{\prime}$ não codificante, tendo esta papel importante na iniciação da transcrição (forma o sítio de entrada do ribossoma). O RNA genômico e algumas proteínas não estruturais associadas, são envoltos em um capsídeo com simetria icosaédrica, sem envelope ${ }^{14} 1737697784$.

Existem sete genótipos (identidade de $85 \%$ ou mais nos nucleotídeos), sendo que três infectam naturalmente primatas não humanos e quatro genótipos que infectam o homem. Os genótipos mais freqüentemente encontrados nas infecções humanas são os genótipos I e III.

O genoma do VHA é semelhante ao dos demais Picornaviridae. A cadeia de RNA tem 7,5Kb e consiste de três regiões: uma região não codificadora na extremidade $5^{\prime}$ de 732 a 740 nucleotídeos, uma parte intermediária, codificadora, com 2.225 a 2.227 nucleotídeos e uma parte não codificadora na extremidade 3' com 40 a 80 nucleotídeos. A Figura 1 revela as diferentes proteínas conhecidas originadas da tradução do segmento intermediário. 


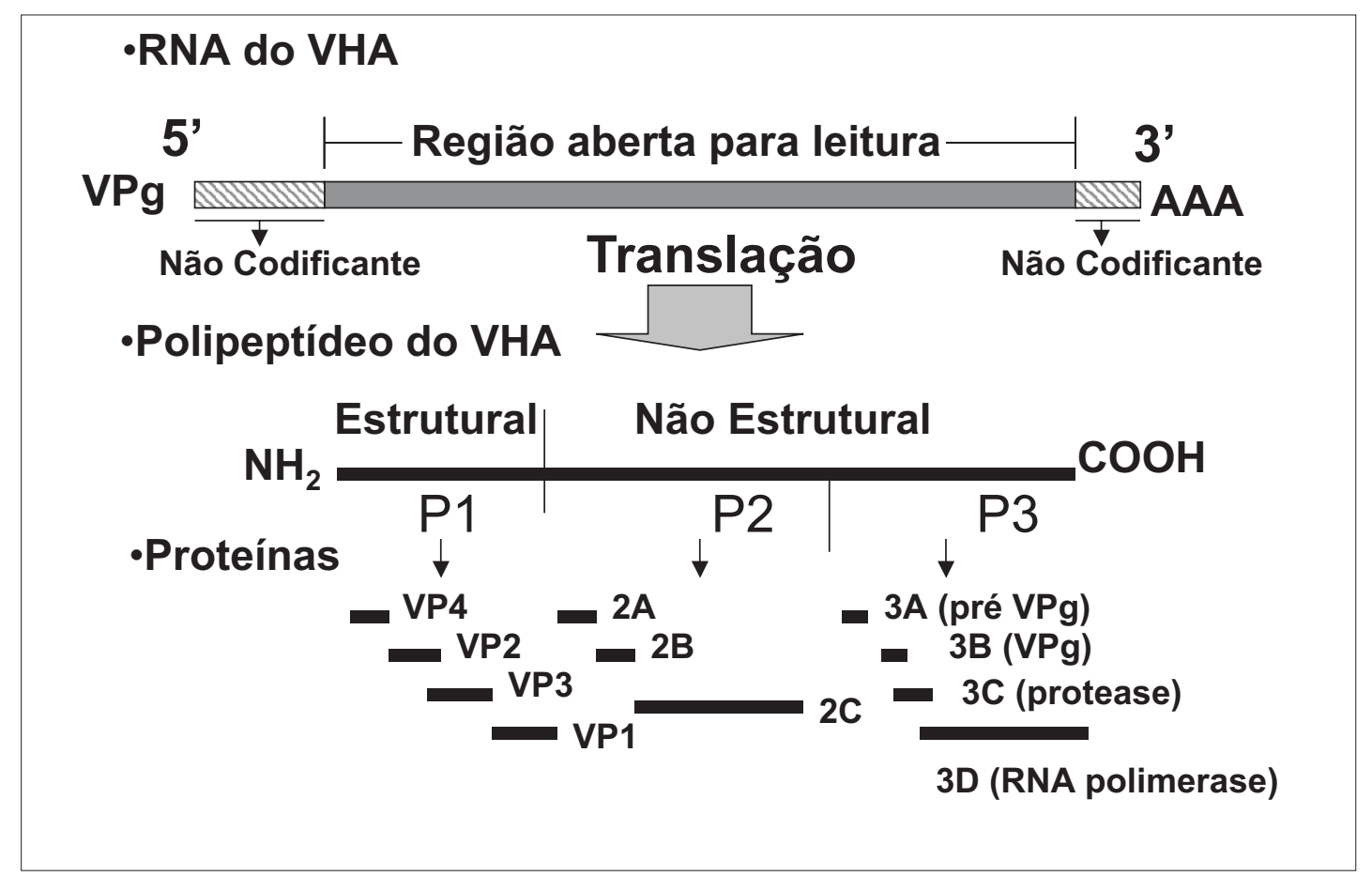

Figura 1- Esquema do RNA do vírus da hepatite A, mostrando as principais proteínas por ele codificadas.

As proteínas estruturais principais são a VP1, VP2, VP3 e VP4. Essas proteínas são originadas da proteína primária, por clivagem pela protease $3 \mathrm{C}$, codificada na região P3, que também codifica a proteína VPg, associada ao RNA (Figura1).

A montagem do vírion no citoplasma começa pela associação das proteínas estruturais VPO (formada pela VP2 e VP4), VP1 e VP3 que formam um complexo iniciador com coeficiente de sedimentação $5 S$. Cinco dessas estruturas se associam e formam um pentâmero de 14S, e 12 desses pentâmeros formarão o capsídeo completo com 70S, que ao envolver o RNA genômico formará partícula de 140S. Os epítopos importantes nas proteínas estruturais, que induzem a formação de anticorpos neutralizadores, são conformacionais e só aparecem após associação das proteínas nas partículas $14 \mathrm{~S}$ e $70 \mathrm{~S}$ ou no virion completo.

\section{CICLO BIOLÓGICO DO VHA}

Após ingestão, o que ocorre com o vírus no aparelho digestivo não é ainda bem conhecido ${ }^{14}$. Estudos em modelos experimentais ${ }^{59} 64$ mostram que o vírus é absorvido, mas pode infectar células epiteliais da mucosa digestiva onde prolifera. Cai na corrente circulatória e chega aos hepatócitos, pela circulação portal e pela circulação sistêmica, através dos espaços inter-endoteliais dos sinusóides e espaço de Disse, sendo capturado pelos hepatócitos através de um possível receptor (uma integrina, mucina símile, de classe I, já identificada em células não hepáticas de primatas não humanos). O vírus se multiplica no hepatócito a partir de uma cadeia de RNA com sentido negativo, originada a partir da cadeia com sentido positivo por ação de uma RNA polimerase viral. O vírus montado é eliminado através da membrana apical do hepatócito, chegando aos canalículos biliares e daí, juntamente com a bile, ao intestino. Pela membrana basolateral chega ao sangue. Os mecanismos de eliminação do vírus na bile e no sangue não são conhecidos, mas independe da necrose do hepatócito, já que altos títulos de vírus são observados nas fezes antes de manifestações clínicas ou laboratoriais da infecção, ou seja, antes de fenômenos de necrose hepatocitária.

\section{CRESCIMENTO DO VHA EM CULTURA}

O vírus tem sido cultivado em células de primatas não humanos e em células humanas, de linhagem hepatocitária ou não. Tem pouco efeito citopático, mas células citotóxicas matam células infectadas in vitro, e interferon gama acrescentado às culturas inibe a replicação viral. Os anticorpos neutralizadores inibem a infecção de células em cultura. 


\section{A RESPOSTA IMUNITÁRIA AO VÍRUS A}

O vírus $A$ induz resposta imunitária humoral (anticorpos) e resposta imunitária celular, ambas importantes nos mecanismos de defesa e, especialmente, a celular na patogênese das lesões ${ }^{14} 1721376979$.

Nas infecções naturais e/ou nas experimentais, os anticorpos da classe $\lg M$ e $\lg A$ são os mais precoces, aparecendo junto com as primeiras manifestações clínicas, mas podem só aparecer no fim da primeira semana de doença. Esses anticorpos persistem, na maioria dos pacientes, não mais do que 4 meses; uma minoria de casos pode ter lgM persistente por até um ano. Geralmente as manifestações clínicas desaparecem antes do desaparecimento da IgM. Os anticorpos IgA também desaparecem em alguns meses e sua participação na resistência à infecção não é conhecida. Os anticorpos lgG aparecem após a primeira semana de doença e persistem provavelmente por toda a vida, ainda que em títulos mais baixos, como seqüela sorológica.

Tanto na classe IgM como na classe lgG estão os anticorpos neutralizadores, que reconhecem epítopos conformacionais formado pelas proteínas estruturais do capsídeo. Os antígenos estruturais isoladamente, são imunogênicos, mas induzem respostas em IgM ou lgG não protetoras (não neutralizadoras), o que tem dificultado a obtenção de vacinas a partir de proteínas recombinates do vírus

Anticorpos IgM e IgG são formados contra outros epítopos das proteínas estruturais e não estruturais, mas não parecem envolvidos nos mecanismos de resistência á infecção e não são detectados nos sistemas comerciais atualmente utilizados para detecção de anticorpos anti-vírus $A$.

A resposta imunitária celular tem sido muito estudada em modelos experimentais de primatas não humanos. Na infecção humana, tem sido estudada através de testes in vitro para avaliar a citotoxicidade de células de pacientes infectados, com ou sem doença, sobre células homólogas ou isólogas infectadas com o VHA. Também através da dosagem de citocinas produzidas por células mononucleares do sangue periférico desses pacientes, estimuladas com o vírus inativado ou por células infectadas.

Em saguis e em macacos infectados tem sido demonstrado que há afluxo de células $T$ e células $B$ nos espaços porta e nos focos intralobulares de necrose, sendo detectadas células $T$ citotóxicas e células $T$ produtoras de IL-4 e IL-6, possivelmente, importantes na ativação das células B para produção de anticorpos no local.

Estudos têm sido feitos a partir da clonagem de células colhidas de fragmentos de biópsias hepáticas de pacientes, obtidas nas fases iniciais da infecção. Tem sido clonadas células CD4+ e CD8+ e, essas últimas, mostram evidente efeito citotóxico sobre fibroblastos autólogos parasitados com o VHA, demonstrando o papel dessas células na patogênese das lesões necróticas. Observa-se grande produção de IFN-gama por aqueles linfócitos e a citocina tem grande efeito inibidor sobre a infectividade do vírus in vitro, o que indica a sua importância não só na agressão hepatocitária mas também na eliminação do vírus.

Estudos com células do sangue periférico de pessoas sadias, com sorologia positiva ou negativa para - VHA, fracionadas e colocadas na presença de células MRC infectadas com o VHA, estimuladas ou não com IL-2, demonstraram que as células citotóxicas naturais (células NK) e células citotóxicas ativadas por linfocinas (LAK, de Lymhokine Actived Killers) são capazes de matar as células infectadas. Essa observação mostra que essas células podem ser participantes da agressão hepatocitária na hepatite aguda, provavelmente nas suas fases mais iniciais, antes da ativação das células CD4 e CD8 específicas. Nesses experimentos foram também utilizadas células de pessoas com hepatite aguda, as quais demonstraram efeito citotóxico muito maior sobre as células parasitadas.

O vírus inativado pelo formol, utilizado como vacina, também ativa linfócitos T CD4+ e CD8+, ativação que já é significativa na segunda semana após a vacinação, indicada pela resposta blastogênica in vitro após estimulação com o vírus. Também induz a produção de IFN-gama nas células mononucleares do sangue periférico, in vitro, bem evidente na quarta semana após a vacinação. Essa observação mostra que a vacina, além de induzir anticorpos neutralizadores, induz também resposta celular, importante na eliminação de células parasitadas pelo vírus.

\section{AS FORMAS DE TRANSMISSÃO DO VHA}

A forma mais comum de transmissão é a oral, através da ingestão do vírus com alimentos ou água contaminados. Nos países subdesenvolvidos a transmissão se dá pela ingestão de água, alimentos e objetos contaminados, e a infecção é precoce, ocorrendo após os oito meses de idade, quando os anticorpos maternos começam a desaparecer. Nos países em desenvolvimento a transmissão clássica por água e alimentos contaminados, precoce, vai diminuindo na medida em que as condições higiênicas vão melhorando, como tem sido observado no Sul e Sudeste do Brasil. Nessas regiões, e nos países desenvolvidos, o número de adolescentes e adultos jovens susceptíveis é grande e surtos epidêmicos podem surgir por ingestão de alimentos contaminados (vegetais, mariscos), em trabalhadores de estações de tratamento de esgoto, em trabalhadores de hospitais, por contato com pacientes com a doença ainda não identificada. Casos 
esporádicos surgem em viajantes para áreas endêmicas, se não tiveram proteção vacinal ${ }^{14} 1737$.

Como o período de viremia é curto e a concentração de vírus no sangue é baixa, a transmissão por sangue ou material com ele contaminado é rara, mas pode ocorrer se o material injetado (soro ou sangue) tiver sido originado de um indivíduo no período de incubação ou na primeira semana da doença. Casos esporádicos têm sido relatados após transfusão sanguínea em neonatos, transfusão de plasma e de plaquetas e de fatores de coagulação e na população usuária de drogas injetáveis.

A transmissão em homossexuais masculinos tem sido suspeitada e alguns surtos epidêmicos foram registrados nessa população. Alguns estudos têm mostrado que altos níveis de soroprevalência de hepatite $A$ em homens homossexuais estão mais relacionadas com contacto oral-anal do que com a orientação sexual ${ }^{4}$.

\section{EPIDEMIOLOGIA}

A hepatite A tem distribuição universal, sendo endêmica em muitas regiões, mas a prevalência da infecção varia muito com o grau de higiene e com as facilidades sanitárias disponíveis para as populações. Quando se analisa a prevalência de sorologia positiva para o anti-VHA total em diferentes regiões do mundo quatro padrões de endemicidade podem ser observados (Figura 2): a) em países pobres, com baixo índice de facilidades sanitárias, a infecção tem incidência muito alta, ocorrendo precocemente e, mais de $90 \%$ da crianças tem sorologia positiva para o VHA no fim da primeira década de vida; nessas regiões a hepatite aguda é menos freqüente nos nativos e as epidemias mostram-se raras; b) em países com melhores condições sanitárias a incidência é intermediária e a curva de distribuição vai se tornando sigmóide, com prevalência mais baixas nas duas primeiras décadas de vida e com pico de prevalência de sorologia positiva para o VHA atingido na fase final da infância e início da adolescência; nessas regiões a hepatite aguda é mais freqüente, representando risco para os susceptíveis não vacinados e surtos epidêmicos podem ocorrer devido à contaminação acidental de alimentos e da água; c) em regiões desenvolvidas a incidência da doença é baixa, com o pico de prevalência de sorologia positiva para o VHA em adultos jovens, sempre em níveis mais baixos do que nas regiões de prevalência intermediária; a incidência da doença é baixa e epidemias podem ocorrer por contaminação acidental de água e alimentos; d) em regiões desenvolvidas, com pouca migração, a incidência pode ser muito baixa e o pico de prevalência de pacientes com sorologia positiva para o VHA ocorre tardiamente, em adultos; nessas áreas a doença é muito pouco freqüente, geralmente adquirida por pessoas que viajaram para áreas de maior endemicidade e os surtos epidêmicos são raros $^{14} 17$.
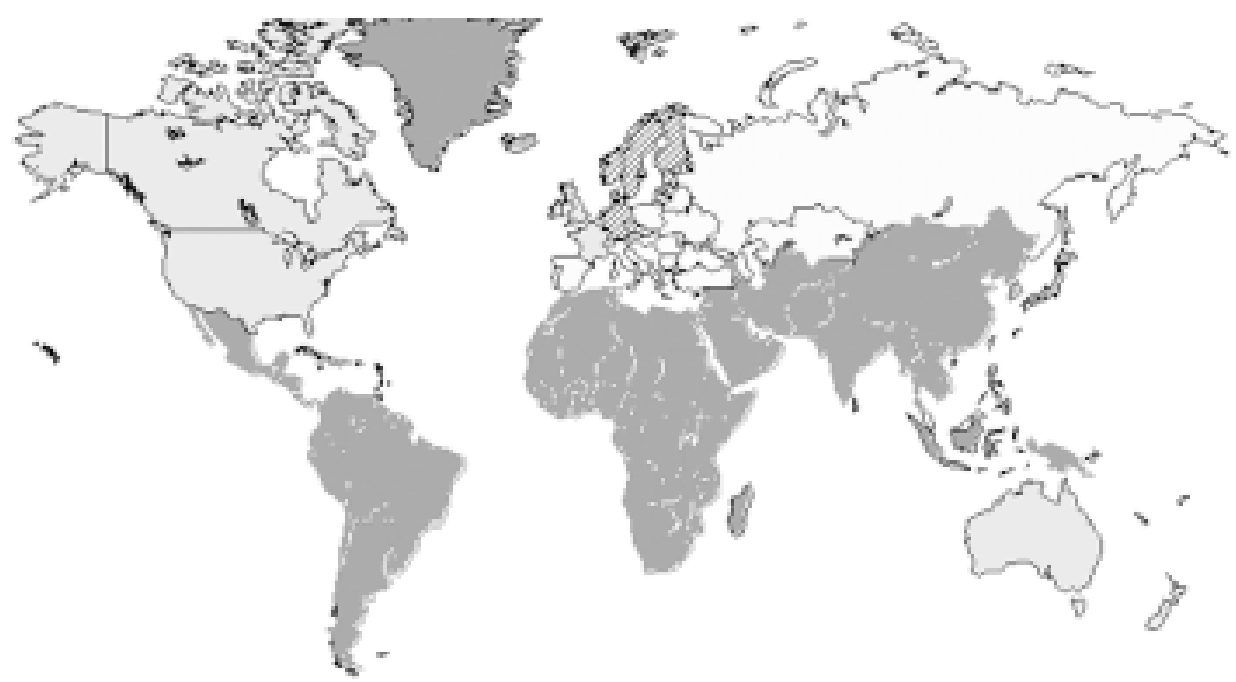

Prevalência

alta Intermediária muito baixa

Figura 2 - Mapa mostrando a incidência da hepatite nas diferentes regiões do mundo.

Uma revisão da literatura publicada sobre a prevalência de anti-VHA total em algumas cidades brasileiras (Figura 3) mostra padrões variáveis: alta prevalência nas regiões Norte e Centro-Oeste 31123556162 , com padrão semelhante aos observados em regiões subdesenvolvidas e prevalência decrescente da região 


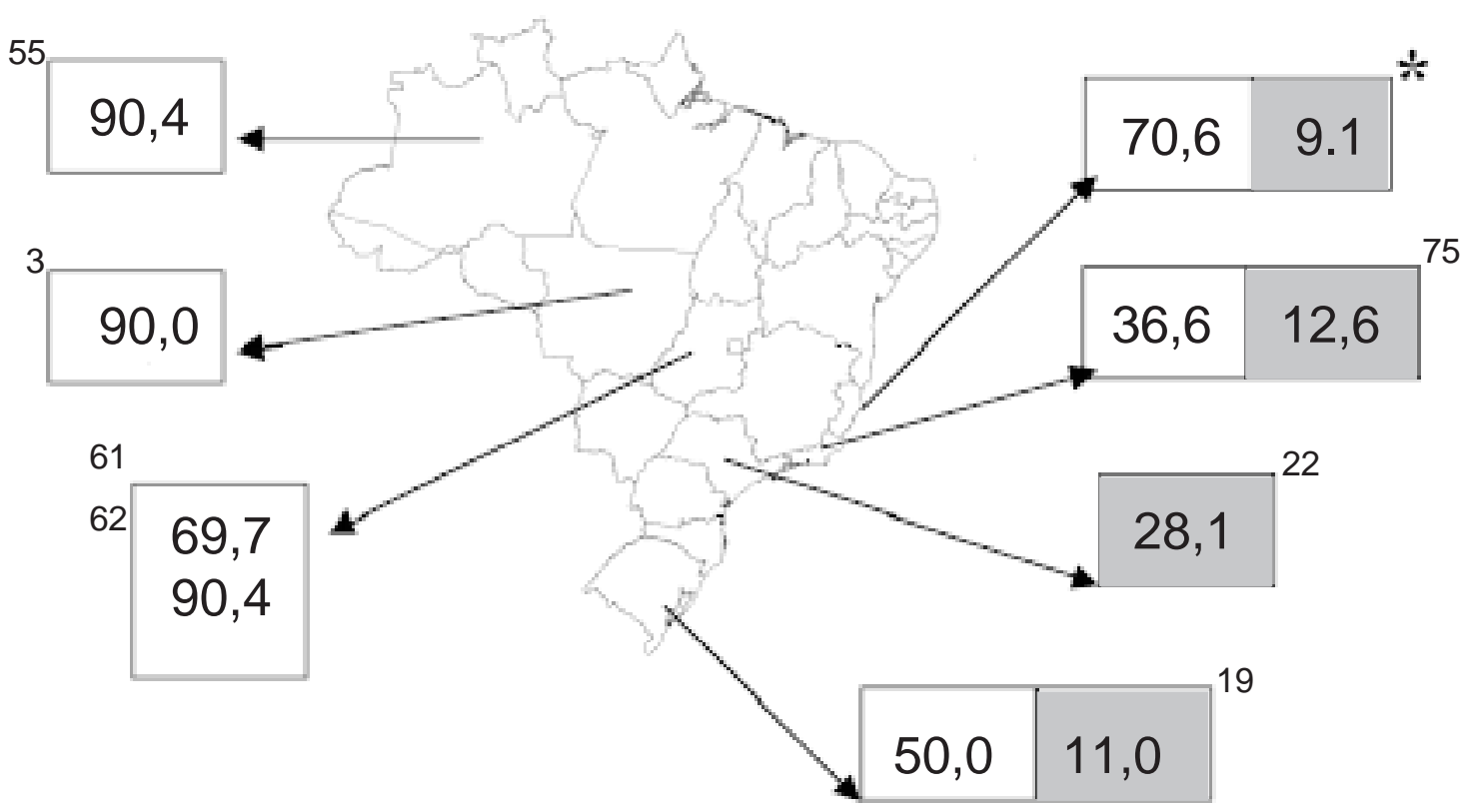

Figura 3 - Prevalência do anti-VHA total em crianças até 10 anos de idade nas diferentes regiões brasileiras onde foram realizadas investigações epidemiológicas. Os nủmeros fora de cada retângulo indicam a rêferência da qual foi retirado o dado. *Zago-Gomes et al, dados não publicados. Os retângulos em branco indicam crianças de baixo nível socioeconômico e os retângulos cinza, criancas de padrão socioeconômico mais elevado. O retângulo branco com a faixa cinza indica que não houve separação do nível socioeconômico na amostra estudada.

Sudeste para a região Sul'1922525357667578 81 83, onde a prevalência na primeira década, mesmo nas populações de mais baixa renda é menor do que a observada na região Norte.

Essas observações epidemiológicas sobre a hepatite A no Brasil tem demonstrado que nas regiões mais desenvolvidas o número de crianças susceptíveis está aumentando muito, não só nas classes mais privilegiadas, mas também nas classes menos favorecidas, fato decorrente das melhores condições sanitárias existentes nessas regiões. Em um estudo recente em escolares de três escolas de ensino fundamental localizadas em três bairros da cidade de
Vila Velha, Espírito Santo, onde vivem famílias de renda alta ou média, baixa e muito baixa, a prevalência do anti-VHA total foi, aos 10 anos de idade, respectivamente $9 \%$, 49,1\% e 61,7\% (Zago-Gomes et al, 2002, dados não publicados; Figura 4). Essa mudança no padrão epidemiológico da hepatite A vem ocorrendo em várias outras regiões do mundo, com aumento de adolescentes e adultos jovens susceptíveis, com idade crescente, aumentando o número de casos da doença nesse grupo etário, levantando a discussão da vacinação para doença nessas regiões, tendo em vista que a gravidade da doença é maior em adultos.

\section{ANATOMIA PATOLÓGICA DA HEPATITE A}

Quando as biópsias hepáticas eram realizadas em pacientes com hepatite aguda, não havia meios de se distinguir com precisão a etiologia ${ }^{46}$. Após o isolamento dos vírus $A$ e $B$, os métodos sorológicos passaram a permitir a identificação da causa dessas hepatites e as biópsias passaram a ser pouco realizadas com finalidade diagnóstica. Um grupo de estudo de hepatites agudas na Dinamarca continuou a realizar biópsias de modo rotineiro até 1980 e esse material pode ser utilizado para estudos das lesões na hepatite aguda A, inclusive comparando com a hepatite B. O estudo de 86 pacientes com hepatite aguda A e 78 com hepatite aguda B mostrou lesões semelhantes, com menor intensidade das lesões lobulares na hepatite B, mas sem diferenças na inflamação portal ${ }^{41}$

Nas formas agudas anictéricas ou ictéricas, consideradas como benignas ou brandas (a grande maioria dos casos), as lesões podem ser observadas nos espaços porta e no interior dos lóbulos. As lesões no interior dos lóbulos se caracterizam por degeneração e necrose de hepatócitos, com exudato inflamatório predominante de mononucleares, mas neutrófilos e eosinófilos podem ser observados. A degeneração hidrópica pode conferir aspecto baloniforme (células claras) ou em célula vegetal. A necrose é focal, lítica, levando ao esfacelo dos hepatócitos, dos quais só se 


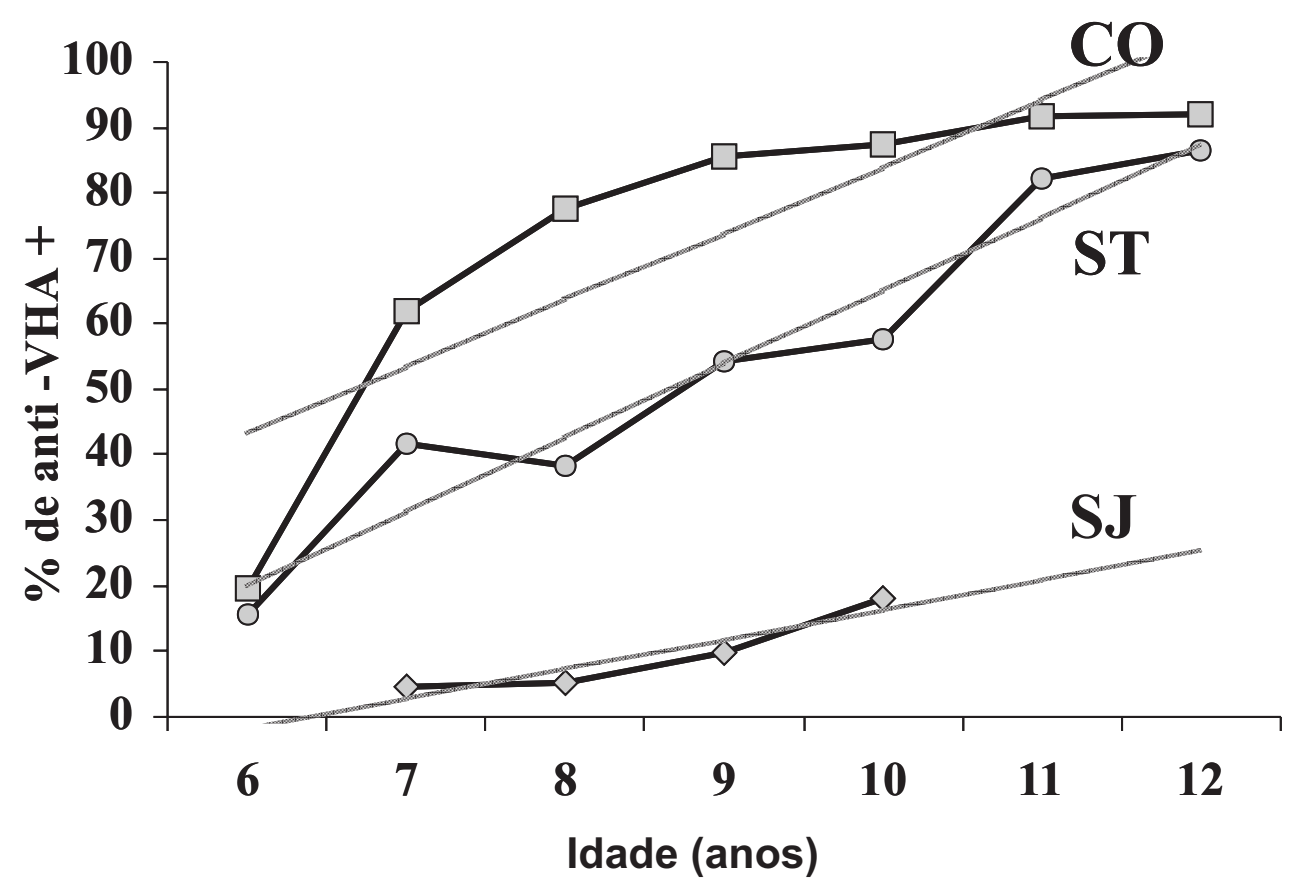

Figura 4 - Prevalência e curvas de tendência do anti-VHA total em escolares da primeira fase do ensino fundamental em três escolas do município de Vila Velha, ES, localizadas em bairros de classe média e alta (renda acima de $R \$ 1700 ;$ escola $S J$ ) e de classe baixa intermediária (renda entre $R \$ 300$ e 700; escola ST) ou muito baixa (renda inferior a $R \$ 300$; escola $C O)$.

pode identificar escassos resquícios do citoplasma. Geralmente é uma necrose de um ou de poucos hepatócitos, levando, juntamente com o edema, o colapso do retículo e a presença das células inflamatórias, a uma destrabeculação dos hepatócitos (desarranjo arquitetural), a qual se recompõe totalmente após a regeneração dos hepatócitos.. A apoptose é freqüente, podendo-se observar células apoptóticas (descritas no passado como degeneração acidofílica, na forma de corpúsculos hialinos de Councilmann) ou, às vezes, pequenos corpos apoptóticos com fragmentos de núcleo. Essas lesões focais são mais freqüentes na zona 3 dos ácinos hepáticos (zona centrolobular), sendo excepcional a necrose confluente, indicativa de forma grave da doença.

Ao lado das lesões degenerativas e necróticas dos hepatócitos, há hipertrofia das células de Kuppfer, que acumulam o pigmento ceróide, possivelmente originado de restos não completamente digeridos dos hepatócitos mortos fagocitados, fato bem evidente pela presença de material PAS positivo no citoplasma daquelas células. Os fenômenos de regeneração hepatocitária -figuras de mitose, poliploidia, binucleação de hapatócitos- são muito evidentes.

Nos espaços porta sempre há um infiltrado de mononucleares, de intensidade variável, mas sem ultrapassar a membrana limitante e sem sinais de agressão aos ductos biliares.
Nas formas colestáticas da hepatite aguda $A$, chama a atenção uma dilatação dos canalículos de Hering, com acúmulo de bile, a qual é também observada no interior dos hepatócitos. A necrose e o desarranjo arquitetural são menos intensos e é maior o número de neutrófilos no exsudato.

Nas formas fulminantes (formas que se acompanham de insuficiência hepática aguda), a necrose é confluente, comprometendo grande parte ou todo o lóbulo (necrose submaciça ou maciça). O infiltrado inflamatório é predominantemente mononuclear, mas pode ser escasso ou desproporcional à extensão da necrose. O colapso do retículo pode ser evidente e pode haver sinais de regeneração hepatocitária. Há geralmente proliferação biliar acentuada.

A hepatite aguda grave, com insuficiência hepática aguda em crianças geralmente apresenta necrose maciça ou submaciça, mas os colapsos do retículo não são extensos, assim como os fenômenos de regeneração. Alguns casos de hepatite fulminante com esteatose microvesicular (hepatite espongiforme ou hepatite de Lábrea) tem sido observado em crianças com IgM anti-VHA, mas não se conhecem as razões que levam a esse tipo de evolução. 


\section{FORMAS CLÍNICAS DA HEPATITE A}

A hepatite $A$ ocorre como infecção esporádica, endêmica ou epidêmica e as formas clínicas de apresentação são semelhantes, independentes de condições geográficas ou raciais 14173769 .

Nas formas esporádicas a idade é muito variável, ocorrendo em crianças e adultos e, especialmente, em regiões não endêmicas. Nas formas epidêmicas as crianças são mais atingidas nas regiões endêmicas, mas é mais freqüente em jovens e adultos nas regiões não endêmicas.

Em qualquer circunstância a infecção com o vírus da hepatite A pode resultar em infecção assintomática, infecção sintomática (oligossintomática) anictérica ou em infecção sintomática ictérica.

Formas assintomáticas e sintomáticas anictéricas são comuns em crianças nas regiões endêmicas. Nessas regiões as crianças tem proteção dos anticorpos maternos até os 8 meses de idade e, a partir daí, a maioria se infectará até os cinco anos de idade. Essas infecções são na sua grande maioria assintomáticas ou oligosintomáticas anictéricas. A freqüência de casos assintomáticos e anictéricos após a infecção não é bem conhecida. Estudos cuidadosos de surtos epidêmicos de hepatite transmitida por alimentos mostraram 14\% de casos assintomáticos e $30 \%$ de casos anictéricos (relação aproximada de 1:3,3) ${ }^{65}$. A relação de casos anictéricos para os ictéricos é menor nas crianças. De fato, um estudo de epidemia em uma comunidade religiosa, onde os expostos eram todos abaixo de 20 anos de idade, a relação de anictéricos para ictéricos foi de $7,5: 1^{56}$. O aparecimento de doentes entre comunicantes de uma família é pequeno entre crianças abaixo dos 3 anos de idade, com o mesmo risco de infecção. A menor freqüência de adultos doentes nessas condições reflete mais a imunidade existente nesse grupo do que a ocorrência de infecção assintomática.

As manifestações clínicas da forma sintomática ictérica aparecem de duas a sete semanas após a infecção (período de incubação), com média de 30 dias. As manifestações prodrômicas podem durar de dois a quinze dias, e em raros casos não são relatadas. Nesses casos a doença se manifesta diretamente pela icterícia. Essas manifestações são indistinguíveis daquelas que ocorrem em outras infecções viróticas e, se a doença for anictérica, o diagnóstico só será feito através da constatação da elevação das enzimas séricas. A medida que a icterícia se instala os sintomas e sinais prodrômicos melhoram e desaparecem.

A duração aproximada da icterícia, dos sinais e sintomas, da eliminação de vírus nas fezes e da viremia está resumida na Figura 5.

A icterícia, geralmente precedida pelo relato de urina escura, aparece de dois a quinze dias após as manifestações prodrômicas. A duração da icterícia é variável, alguns relatando média de 7 dias (4 a 22 dias em uma série de casos), mas extensão da icterícia por períodos médios maiores foi relatada em outras séries de casos. Além de mais freqüente, a icterícia nos adultos tem duração maior. As taxas séricas de bilirrubina são variáveis, e média de $6,7 \mathrm{~g} / \mathrm{dL}$ foi relatada em série de casos, todos ictéricos, em New York ${ }^{30}$. Dos sinais, a hepatomegalia discreta e sensível, é o mais freqüente, aparecendo em $85 \%$ dos casos enquanto a esplenomegalia e a linfoadenomagalia são menos comuns ( $15 \%$ dos casos).

\section{HEPATITE AGUDA A}

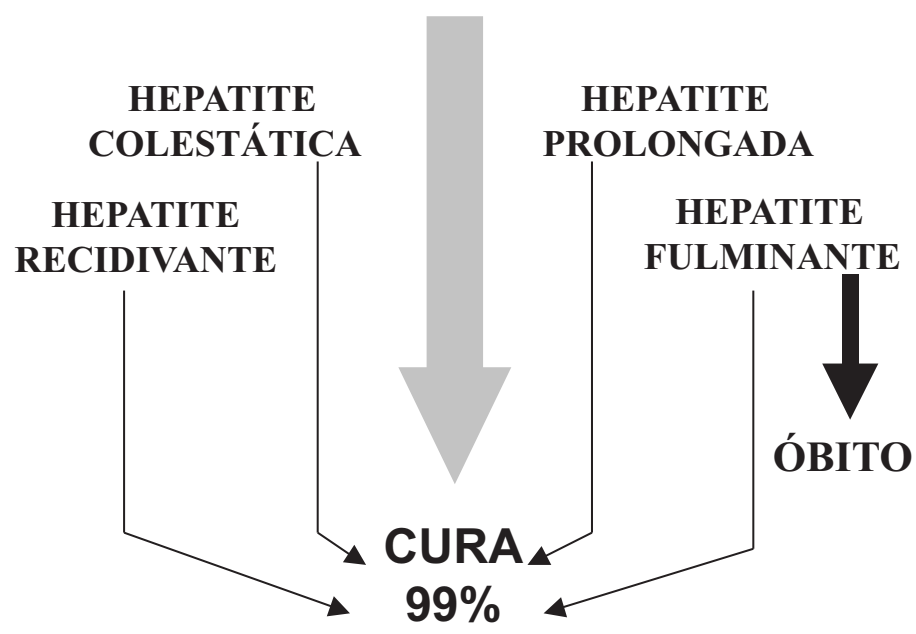

Figura 5- Esquema resumindo a evolução da hepatite $A$. 
A evolução da hepatite $A$ é de modo geral muito boa, terminando com a cura na grande maioria de casos, mesmo nas formas mais atípicas (Figura 6). A mortalidade mostra-se baixa em jovens, aumentando muito se a doença é adquirida a partir da quarta década da vida. A duração da doença revela-se variável, com média de 15 dias em algumas observações bem controladas, mas com predomínio de crianças. Na série de casos da Universidade de Yale (infecção em voluntários) a duração da doença variou de 7 a 87 dias com média de 30 dias. Não têm sido relatadas complicações mais graves durante a gravide ${ }^{48}$ e a evolução da doença parece não se alterar se a infecção é concomitante com a síndrome da imunodeficiência adquirida.

A recorrência ou recidiva ${ }^{7}$ da hepatite $A$ mostra-se rara (3 de 200 pacientes na série descrita por Havens ${ }^{27}, 17 / 256$ na Argentina ${ }^{71}$ e $7 / 59$ diagnosticados na Califórnia entre 1985-9476). O diagnóstico de recidiva deve ser feito com reserva, sendo necessário eliminar a possibilidade de infecção com outro vírus hepatotrópico. A detecção do vírus nas fezes por técnicas de hibridização ou imuno-microscopiaeletrônica confirma a recidiva. O quadro clínico da doença na recidiva geralmente não difere daquele da doença inicial, mas há tendência a maior colestase.

Uma forma prolongada da hepatite A tem sido relatada, com duração dos sintomas (icterícia) por até 120 dias. Em série de casos de uma epidemia na Califórnia, o curso prolongado, acima de 14 semanas foi observado em 11/130 casos $^{65}$. Nesses casos a biópsia hepática mostrou inflamação portal, necrose periportal em saca-bocados, focos necro-inflamatórios intra-lobulares e moderado grau de fibrose. Todos os pacientes apresentaram normalização dos testes bioquímicos até o quinto mês de evolução.

Não é incomum que pacientes que tiveram hepatite A prolongada venham a se queixar de fadiga por um período de até um ano após o desaparecimento dos sintomas.

Algumas observações têm mostrado que nas formas prolongadas da hepatite A pode existir excreção persistente do vírus, razão pela qual os pacientes nessa situação devem ser considerados como potenciais transmissores.

Uma forma colestática de hepatite A tem sido descrita. Essa forma se caracteriza por níveis elevados de bilirrubina, prurido acentuado, diarréia, má absorção intestinal e perda de peso. A resolução espontânea constitui a regra, sem necessidade de intervenção medicamentosa. As formas colestáticas tendem a se prolongar ${ }^{25}$.

A forma fulminante da hepatite $A$ não é freqüente. Nos países desenvolvidos a insuficiência hepática aguda por hepatite A mostra-se rara, sendo mais freqüente em adultos do que em crianças, tendo sido observada em 20/295 casos relatados em estudo retrospectivo recente nos Estados Unidos ${ }^{68}$. Nos países em desenvolvimento e subdesenvolvidos a freqüência de insuficiência hepática aguda em crianças, decorrente de formas agudas de hepatite A revela-se mais comum,

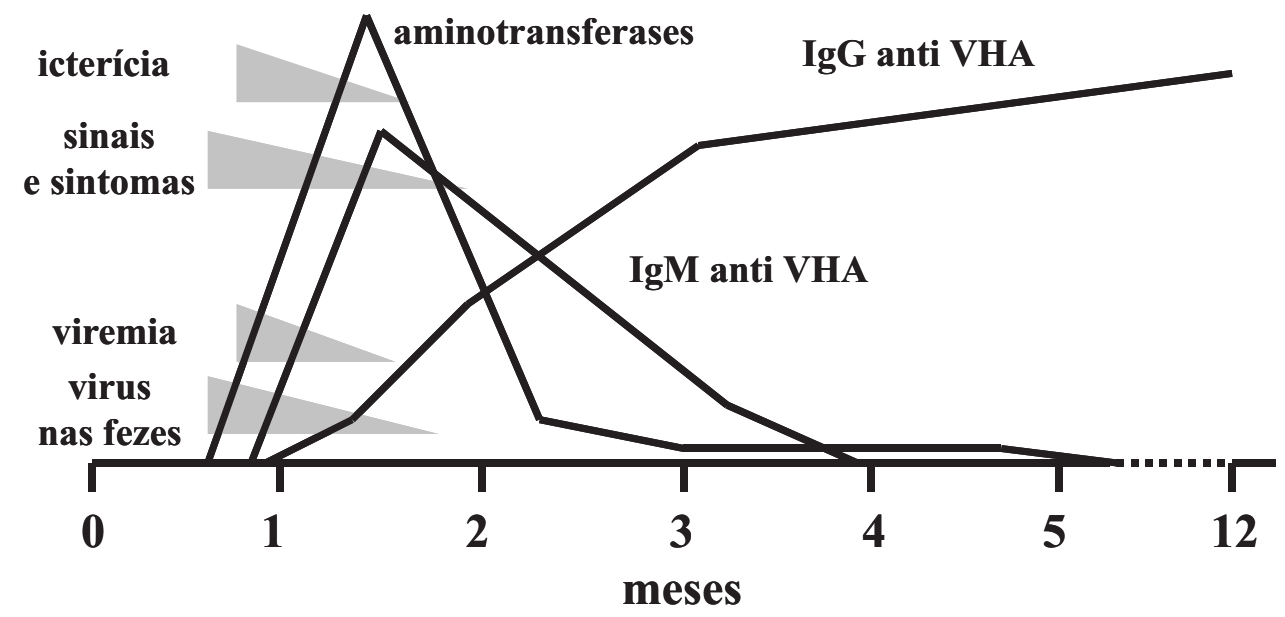

Figura 6 - Esquema mostrando a evolução da presença do vírus nas fezes, da viremia, da icterícia, dos sinais e sintomas, dos nívels séricos das aminotransferases e dos anticorpos lgM e IgG em um caso típico de hepatite $A$.

representando mais de $50 \%$ dos casos no Chile, Argentina e Paquistão. Em nosso meio existe apenas um relato sobre insuficiência hepática aguda em crianças atendidas em Hospital pediátrico de Vitória, ES, onde anticorpos IgM anti-vírus da hepatite A estavam presentes em $70 \%$ de 46 casos $^{51}$.
A mortalidade entre todos os casos de hepatite A é baixa, aproximando-se de 1,5\% de todos os casos ictéricos internados nos Estados Unidos (381 mortes entre cerca de 30000 casos hospitalizados no período 1983-1987) A idade é fator importante, sendo maior a mortalidade entre adultos acima de 40 anos $^{42}$. Em 
epidemia urbana em Tenessee, EEUU, entre 1994 e 1995 , de 256 casos internados, 3 desenvolveram insuficiência hepática aguda e 2 faleceram ${ }^{14}$. Nos países em desenvolvimento a mortalidade parece ser menor. Em recente epidemia em Shangai ocorreram 292.301 casos entre Janeiro e Março de 1988, tendo ocorrido apenas 32 óbitos $(0,01 \%)^{26}$. Provavelmente o menor número de adultos acometidos (já com proteção natural) tenha sido responsável pela baixa mortalidade observada.
Nas formas graves (fulminantes) com insuficiência hepática, a mortalidade relatada nos Estados Unidos foi de $65 \%$, para todas as idades. Não temos dados seguros sobre a mortalidade na forma fulminante em todas as idades nos países em desenvolvimento e no Brasil. Nessas regiões, em crianças a mortalidade é menor, tendo sido próxima de $50 \%$ nos relatos do Chile, Argentina, Paquistão e Vitória, ES ${ }^{51}$.

\section{FATORES DE RISCO PARA HEPATITE A FULMINANTE}

Não são conhecidos, mas algumas observações têm mostrado que pacientes com doença hepática crônica tem maior risco ${ }^{36}$. Por essa razão recomenda-se a vacinação para esses pacientes, se não foram expostos ao vírus ${ }^{36}$. Maior freqüência de formas graves de hepatite A em pacientes com infecção pelo vírus $C$ relatada por alguns autores, especialmente na Itália, não foram confirmadas em outras observações ${ }^{14} 80$.

\section{FORMAS CRÔNICAS DE HEPATITE A}

Se existem, são raras. Há relato de paciente com enzimas persistentemente elevadas e eliminação de vírus nas fezes por períodos de 11 meses, apresentando inflamação portal, com necrose periportal e fibrose. Aos 25 meses, o paciente desenvolveu varizes esofageanas e apresentava IgM anti-VHA aos 31 meses após o inicio da doença ${ }^{32}$. Nesse caso, ainda que relatado como hepatite $A$ crônica, pode ter havido uma hepatite $A$ prolongada, com superposição de outra doença hepática crônica. O fato de ter havido detecção de IgM
anti-VHA tardiamente não se refere à cronicidade, pois tal fato tem sido relatado até 30 meses após o início da doença aguda, quando pesquisado com métodos mais precisos e com diluições menores do soro ${ }^{34}$.

Uma doença hepática crônica pode seguir uma hepatite aguda $A$, mas sem relação direta com essa infecção. Há poucos relatos de desencadeamento de hepatite auto-imune após hepatite aguda $A$, sendo que muitas vezes o que existe é a superposição das duas doenças.

\section{MANIFESTAÇÕES EXTRA-HEPÁTICAS DA HEPATITE A}

Podem ocorrer mas são raras. Hemólise, colestase acalculosa, derrames pleurais e pericárdicos, artrite reativa, pancreatite e manifestações neurológicas têm sido relatadas ${ }^{14}$

A hemólise pode ser precipitada em pacientes com deficiência de G-6-PD, mas pode ocorrer sem a presença do defeito enzimático. Pode estar relacionada a auto-anticorpos (anti-triose-fosfato isomerase). Hipoplasia medular com anemia aplástica tem sido raramente relatada.

Casos de pancreatite foram descritos em formas fulminantes e raramente em formas agudas brandas.
Manifestações decorrentes da presença de imunocomplexos têm sido relatadas: vasculite cutânea, artrite e crioglobulinemia, desaparecendo as manifestações com o desaparecimento das manifestações da hepatite.

Nefrite intersticial, glomerulonefrite mesangioproliferativa e necrose tubular aguda, possivelmente por ação de imunocomplexos têm sido descritos em formas benignas, não acompanhadas de insuficiência hepática.

Quadro de neurite, síndrome de Guillan-Barré, mielite transversa e encefalite pós-infecção viral têm sido descritos e podem ser decorrentes de vasculite comprometendo setores do sistema nervoso central e periférico.

\section{DIAGNÓSTICO LABORATORIAL DA HEPATITE A}

Não existem alterações laboratoriais que sejam típicas da hepatite aguda $A^{14173767}$. A elevação das aminotransferases (transaminases) ocorre já na fase prodrômica, alcançando o limite máximo no auge dos sintomas. Não há relação entre elevação de transaminases e prognóstico da doença. Na maioria das vezes os níveis de TGP não ultrapassam $500 \mathrm{Ul}$ e a bilirrubina fica abaixo de $10 \mathrm{mg} / \mathrm{dL}$. Os melhores indicadores de prognóstico são a atividade de protrombina e os níveis de bilirrubina. Em dois meses, $60 \%$ dos pacientes já têm testes bioquímicos normais, chegando a quase $100 \%$ em 6 meses. Há relatos raros de elevação de transaminases e bilirrubinas por mais de 12 meses.

O diagnóstico etiológico é feito pela pesquisa dos anticorpos anti-VHA da classe IgM, geralmente, por método de ELISA por competição ou radioimunoensaio, com vários kits disponíveis no mercado ${ }^{43}$. A especificidade da detecção do IgM anti-VHA para o diagnóstico da hepatite aguda $A$ foi de $99 \%$, a sensibilidade de $100 \%$ e o valor preditivo positivo foi de $88 \%$, em uma série de casos estudados tendo como 
controle doadores voluntários de sangue ${ }^{74}$. Se o teste é negativo com o início dos sintomas a sua repetição após uma semana tende a dar resultados positivos.

A positividade do anti-A IgM em geral dura quatro meses, podendo chegar a 6 meses em $5 \%$ dos casos. Raramente, persiste por mais de 12 meses. Geralmente as enzimas séricas normalizam-se antes da negativação do $\lg \mathrm{M}^{35}$.

A pesquisa do vírus nas fezes pode ser feita por PCR ou por imuno-eletro-microscopia, mas possui pouco valor como método de rotina para o diagnóstico, pois geralmente a excreção viral se reduz drasticamente e tende a desaparecer após os sintomas. Essa pesquisa se justifica para esclarecer casos arrastados da doença, inclusive para confirmação da etiologia.

Ainda que a avaliação de anticorpos não seja rotina após a vacinação, ela pode ser feita utilizando-se testes de ELISA para anti-HVA total, embora os títulos de anticorpos não sejam tão altos como na infecção natural. Um teste para pesquisa de anti-VHA total na saliva está sendo desenvolvido e poderá ser útil como método não invasivo para avaliação do estado imunitário antes da vacinação.

\section{TRATAMENTO}

É sintomático. A dieta é normal e o repouso relativo. Nenhum medicamento, exceto os sintomáticos, devem ser prescritos. O acompanhamento deve ser feito pela dosagem periódica de transaminses e bilirrubinas, com o paciente tendo alta quando os valores das transaminases estiverem normais ou próximo ao normal. Em relação ao repouso, vale a pena assinalar que não existe nenhuma evidencia de que possa melhorar a evolução da doença. A orientação ao doente sobre atividade física deve basear-se no senso comum.

Nos casos em que a doença se arrasta ou apresenta recidiva a orientação é a mesma. Em formas colestáticas prolongadas o uso de corticosteróides (30mg de prednisona), com retirada em trinta dias tem sido preconizado para acelerar o desaparecimento da icterícia e do prurido. Esse é certamente um assunto controvertido. Como a evolução espontânea para a cura é a regra o uso de corticosteróides deve ser encarado como medida excepcional. Importante é excluir doença obstrutiva biliar com exame de imagem. O uso de colestiramina está indicado para o controle do prurido.

Nos casos graves com insuficiência hepática aguda o paciente deve ser internado em unidade de tratamento intensivo e o transplante hepático tem que ser considerado.

\section{PREVENÇÃO}

A prevenção da hepatite depende de cuidados gerais e imunoprofilaxia passiva e/ou ativa.

O vírus é inativado pela fervura (20 minutos), cloração, luz ultravioleta e por formalina (1:4000) Os cuidados gerais incluem a lavagem das mãos, o que pode impedir a disseminação do vírus. Aos viajantes para áreas de grande endemicidade recomenda-se medidas gerais de higiene: lavar as mãos, cuidados com a água, gelo, frutas e verduras cruas e mariscos inadequadamente cozidos.

A imunoprofilaxia passiva ${ }^{14} 17$ é feita com a injeção intramuscular de gamaglobulina anti-A, antes da exposição, o que previne 85 a $95 \%$ dos casos. Se utilizada uma a duas semanas após a exposição, pode prevenir ou atenuar a doença. Mas, após duas semanas do contacto, não apresenta eficácia. A dose fica entre $0,02 \mathrm{ml} / \mathrm{kg}$ de peso corporal (o que confere proteção por aproximadamente três meses) e $0,06 \mathrm{ml} / \mathrm{kg}$ (que confere proteção de quatro a seis meses) ${ }^{1014}$. A imunoglobulina pode ser aplicada em crianças abaixo de 2 anos de idade na dose de $0,02 \mathrm{ml} / \mathrm{kg}$.

O uso da imunoglobulina anti-A está indicado para grupos de risco: viajantes para áreas endêmicas e contatos domiciliares. Contatos fora do domicílio não necessitam imunoprofilaxia passiva, exceto quando existem fontes comuns de disseminação da doença.

A imunoprofilaxia ativa é feita com a utilização de vacina. A vacina com o vírus vivo, atenuado, foi desenvolvida, mas o risco potencial de contaminação com cepas virulentas e o aparecimenro de efeitos colaterais, desaconselhou o seu uso. Vacinas utilizando antígenos do vírus obtido por técnicas de engenharia genética ainda não foram conseguidas. A dificuldade está no fato de que, embora imunogênicas, as proteínas estruturais dos vírus isoladas não induzem anticorpos protetores. Estes dependem de epítopos conformacionais, que surgem após a montagem da estrutura do vírus. Recentemente conseguiu-se, com a transfecção do DNA complementar do RNA do vírus para células cultivadas, que houvesse expressão das proteínas estruturais, as quais se organizaram nas estruturas tridimensionais que formam o capsídeo do vírus, sem que tenha havido transcrição do RNA viral. Formaram-se vírus vazios, (partículas de 14S e 70 S) que se mostraram imunogênicos, produzindo anticorpos neutralizadores em animais de experimentação ${ }^{72}$. Também esses antígenos se mostraram muito eficazes para a montagem de testes diagnósticos (ELISA). É possível que, em futuro muito próximo, uma vacina e testes de ELISA, utilizando esses antígenos recombinantes estejam disponíveis no mercado.

Atualmente, existem duas vacinas no mercado, produzidas com o vírus inativado pela formalina: HAVRIX (Smith KlineBeegham Biologicals) e VAQTA (Merck \& Co, Inc), ambas licenciadas para crianças acima de dois anos de idade, existindo em formulação pediátrica (licenciadas para $<19$ e $<18$ anos respectivamente) e para adultos 510133844 . 
As duas vacinas são altamente imunogênicas e possuem grande eficácia, induzindo soro-conversão em 90 a $98 \%$, após uma dose e, em $100 \%$, após duas doses. Os níveis de anticorpos considerados protetores persistem pelo mínimo até seis anos em adultos e, se estima, pelo estudo de modelos matemáticos da cinética do decréscimo dos anticorpos, que a proteção pode persistir até por 20 anos. Alguns poucos estudos demonstram que a vacina pode ser administrada com outras vacinas (por exemplo em viajantes) e juntamente com a gamaglobulina. Efeitos adversos importantes, após a aplicação da vacina não têm sido descritos.

A vacina é aplicada em duas doses com intervalo de seis meses. Deve ser recomendada para viajantes para áreas endêmicas, homossexuais masculinos, usuários de drogas endovenosas, pacientes com hepatopatia crônica e pessoas que trabalham em ocupação de risco de infecção ${ }^{10}$. A avaliação de exposição prévia antes da vacinação é discutida e está relacionada ao custo do exame e da vacina. Se o custo do exame for bem inferior ao da vacina, pode-se fazer o teste, o que leva à economia de recursos, especialmente em áreas onde o risco de infecção é maior ${ }^{2}$.

Atualmente, já existe uma vacina que associa os antígenos dos vírus $\mathrm{A}$ e $\mathrm{B}$, com eficácia comprovada ${ }^{63}$.

$A$ vacinação em massa ainda é discutível tendo em vista o alto custo da vacina. É possível que com o desenvolvimento de vacinas recombinantes o custo caia e torne possível a vacinação de todas as crianças. Tendo em vista os gastos com internação de pacientes com hepatite $\mathrm{A}$ alguns autores acreditam que há um custobenefício favorável, sob o ponto de vista econômico, para a vacinação em massa das crianças nos países desenvolvidos, mas essa análise tem sido questionada por autores que mostraram ausência de custo-eficácia na vacinação em massa ${ }^{6}$.

\section{REFERÊNCIAS BIBLIOGRÁFICAS}

1. Abuzwaida ARN, Sidoni M, Yoshida CFT, Schatzmayr HG. Seroepidemiology of hepatitis $A$ and $B$ in two urban communities of Rio de Janeiro, Brazil. Revista do Instituto de Medicina Tropical de São Paulo 29:219-223, 1978.

2. Arguedas MR, Heudebert GR, Fallon MB, Stinnet AA. The cost effectiveness of hepatitis $A$ vaccination in patients with chronic hepatitis C viral infection in the United States. American Journal of Gastroenterology 97:721-728, 2002.

3. Assis SB, Souto FDS, Fontes CJF, Gaspar AMC. Prevalência da infecção pelos vírus das hepatites $\mathrm{A}$ e $\mathrm{E}$ em escolares de município da Amazônia Matogrossense. Revista da Sociedade Brasileira de Medicina Tropical 35:155-158, 2002.

4. Ballesteros J, Dal-Re R, Gonzalez A, del Romero J. Are homosexual males a risk group for hepatitis $A$ infection in intermediate endemic areas? Epidemiology of Infectious Diseases 117: 145-148, 1996.

5. Bell BF. Hepatitis A vaccine. Pediatric Infectious Diseases Journal 19:1187-1188 2000

6. Beutels P, Edmunds WJ, Antonanzas F, De Wit GA, Evans D, Feilden R, Fendrick AM, Ginsberg GM, Glick HA, Mast E, Pechevis M, Van Doorslaer EK, van Hout BA. Viral Hepatitis Prevention Board. Economic evaluation of vaccination programmes: a consensus statement focusing on viral hepatitis. Pharmacoeconomics 20:1-7, 2002

7. Bornstein JD, Byrd DE, Trotter JF. Relapsing hepatitis A: a case report and review of the literature. Journal of Clinical Gastroenterology 28:355-356,1999

8. Bradley DH, Fields HÁ, MacCustland KA, Maynard JE, Decker $\mathrm{RH}$, Whittington R, Overby LR. Serodiagnosis of viral hepatitis $A$ by a modified competitive binding radioimmunoassay for immunoglobulin $\mathrm{M}$ anti-hepatitis $\mathrm{A}$ virus. Journal of Clinical Microbiology 9:120-127,1979.

9. Cameron JDS. Infective hepatitis. Quarterly Journal of Medicine 12:139-155, 1943.

10. CDC. MMWR. Prevention of Hepatitis A through active or passive immunization: Recommendations of the Advisory Committee on Immunization Practices 48:1-37, 1999.
11. Clemens SAC, Fonseca JC, Azevedo T, Cavalcanti A, Silveira TR, Castilho MC, Clemens R. Soroprevalência para hepatite A e B em quatro centros no Brasil. Revista da Sociedade Brasileira de Medicina Tropical 33:1-10, 2000.

12. Cockayne EA. Catarrhal jaundice, sporadic and epidemic and its relation to acute yellow atrophy of the liver. Quarterly Journal of Medicine 6: 1-29, 1912.

13. Croweroft NS, Walsh B, Davison KL, Gungabisson U, PHLS Advisory Committee on Vaccination and Immunisation (London). Guidelines for the control of hepatitis A virus infection. Communicable Disease and Public Health 4:213-227 2001.

14. Cuthbert JA. Hepatitis A: old and news. Clinical Microbiology Reviews 14:38-58, 2001.

15. Dible JH, McMichel J, Sherlock SPV. Pathology of acute hepatitis: aspiration biopsy studies of epidemic, arsenotherapy and serum jaundice. Lancet ii: 402-408, 1943.

16. Editorial não assinado. Homologous serum hepatitis. Lancet ii: 691-692, 1947

17. Feinstone SM, Gust ID. Hepatitis A virus. In: Mandell GL, Bennet JE, Dolin R (eds) Principles and Practice of Infections Diseases. $5^{\text {th }}$ edition Churchill Livingstone, p1920-1940, 2000.

18. Feinstone SM, Kapikian MAS,Purcell RH. Hepatitis A: detection by immunoelectronmicroscopy of a virus like antigen associated with acute illness. Science 182:1026-1028, 1973.

19. Ferreira CT, Pereira Lima J, Barros FC. Serum epidemiology Hepatitis A virus in two socioeconomically distinct populations groups of Porto Alegre. Gastroenterologia e Endoscopia Digestiva 15:85-90, 1996

20. Findlay GM, Dunlop JL, Brown HC. Observations on epidemic catarrhal jaundice. Transactions of the Royal Society of Tropical Medicine and Hygiene 25:7-24, 1931.

21. Fleisher B, Fleisher S, Maier K, Wiedemann KH, Scaher M, Thale $H$, Valbracht $A$. Clonal analysis of infiltrating $T$ lymphocytes in liver tissue in viral hepatitis A. Immunology 69:14-19,1990.

22. Focaccia R, Conceição OJG, Sette Jr H, Sabino E, Bassit L, Nitrini DR, Lomar AV, Lorenço R, Souza FV, Kiffer CRV, Santos EB, Gonzales MP, Saéz-Aquezar A, Riscal JR, Fischer D. 
Estimated prevalence of viral hepatitis in the general population of the municipality of São Paulo, measured by a serologic survey of a stratified, randomized and residence-based population. The Brazilian Journal of Infectious Diseases 2:269-284, 1998.

23. Gayotto LC, Quarentei AA, Cabral GL. Soroepidemiologia das hepatites $A$ e $B$ nas regiões dos rios Biá e Alto Juruá, Amazônia Ocidental. Gastroenterologia e Endoscopia Digestiva 3:106-112,1984.

24. Gellis SS, Stokes Jr J, Brother GM, Hall WM, Gilmore HR, Reyer $E$, Morrissey RA. The use of human immune serum globulin (gamma globulin) in infectious (epidemic) hepatitis in Mediterranean theater of operations. 1. Studies on prophylaxis in two epidemics of infectious hepatitis. Journal of the American Medical Association 128: 1062-1063, 1945.

25. Gordon SC, Reddy KR, Schiff L, Schiff ER. Prolonged intrahepatic cholestasis secondary to acute hepatitis A. Annals of Internal Medicine 101: 635-637, 1984.

26. Halliday ML, Kang LY, Zhou TK, Hu MD, Pan QC, Fu TY, Huang YS, Hu SL. An epidemic of hepatitis A attributable to the ingestion of raw clams in Shanghai, China. Journal of Infectious Diseases 164:852-859, 1991

27. Havens Jr WP. Infectious hepatitis in middle-east: a clinical review of 200 cases seen in a military hospital. Journal of the American Medical Association 126:17-23,1944.

28. Havens Jr WP, Paul JR. Prevention of infectious hepatitis with gamma globulin. Journal of the American Medical Association 129:270-272,1945.

29. Havens Jr WP, Ward R, Drill VA, Paul JR. Experimental production of hepatitis by feeding icterogenic materials. Proceedings of Society of Experimental Biology and Medicine. 57:206-208, 1944.

30. Hoagland CL, Shank RE. Infectious hepatitis: a review of 200 cases. Journal of the American Medical Association 130:615621,1946

31. Holmes AW, Wolfe L, Rosenblate H, Deinhardt F. Hepatitis in marmosets: induction of disease with coded specimens from human volunteer study Science 165:816-817, 1969.

32. Inoue K, Yoshiba M, Yotsuyanagi H, Otsuka T, SekiyamaK, Fujita R. Chronic hepatitis A with persistent viral replication. Journal of Medical Virology 50:322-324, 1996.

33. Iversen P, Roholm K. On aspiration biopsy of the liver, with remarks on its diagnostic significance. Acta Medica Scandinavica 102:1-16 1939.

34. Jacobs RJ, Meyerhoff AS. Comparative cost effectiveness of varicella, hepatitis $A$, and pneumococcal conjugate vaccines. Preventive Medicine 33:639-645 2001.

35. Kao HW, Ashcavai M, Redeker AG. The persistence of hepatitis A IgM antibody after acute clinical hepatitis A. Hepatology 4:933936,1984.

36. Keefe EB. Is hepatitis A more severe in patients with chronic hepatitis B or other chronic liver disease? American Journal of Gastroenterology 90:201-205, 1995.

37. Kemmer NM, Miskowisky EP. Hepatitis A. Infectious Diseases Clinics of North America 14:605-618 2000.

38. Koff RS. Hepatitis vaccines. Infectious Diseases of North America 15:83-95, 2001

39. Krugman S, Ward R, Giles GP. The natural history of infectious hepatitis. American Journal of Medicine 32:717-728, 1962.
40. Krugman S, Ward R, Giles GP, Bodanski D, Jacobs AM. Infectious hepatitis: detection of virus during the incubation period and in clinically inapparent infection. New England Journal of Medicine 261:729-734, 1959.

41. Kryger P, Christoffersen P. Liver histopathology of the hepatitis $A$ virus infection: a comparison with hepatitis $B$ type and non Anon B. British Journal of Clinical Pathology 36:650-654, 1983.

42. Kyrlagktsis Icramp ME, Smith H, Portmann B, O'Grady J. Acute hepatitis A virus infection: a review of prognostic factors from 254 years experience in a tertiary referral center. Hepatogastroenterology 49:524-528 2002.

43. LaBrecque FD, LaBrecque DR, Klinzman D, Perlman S, Cederna JB, Winokur PL, Han JQ, Stapleton JT. Recombinant hepatitis A virus antigen: improved production and utility for diagnostic immunoasssay. Journal of Clinical Microbiology 36:2014-2018, 1998.

44. Lemon SM, Thomaz DL. Vaccines to Prevent Viral Hepatitis. New England Journal of Medicine 336:196-204, 1997.

45. MacCallum FO, Bradley WH. Transmission of infective hepatitis to human volunteers. Lancet 2:228, 1944.

46. Mallory TB. The pathology of epidemic hepatitis. Journal of American Medical Association 134: 655-662, 1947.

47. McDonald S. Acute yellow atrophy of the liver. Edinburgh Medical Journal 1:83-88 1908

48. Michielsen PP, van Damme P. Viral hepatitis and pregnancy. Acta Gastro-enterologica Belgica 62:21-29 1999.

49. Midthun KE, Ellerbeck E, Gershman K, Calandra G, Krab D, McCaughtry M, Nalin D, Provost P. Safety and immunogenicity of a live attenuated hepatitis $A$ virus vaccine in seronegative volunteers. Journal of Infectious Disease 163:735-739 1991.

50. Miller WJ, Provost PJ, McAleer WJ, Ittensohn OL, Villarejos VM. Hillmean MR. Specific immune adherence assay for human hepatitis A antibody. Application to diagnostic and epidemiologic investigations. Proceedings of the Society of Experimental Biology and Medicine 149:254-261, 1975.

51. Moreira-Silva SF, Frauches DO, Almeida AL, Mendonça HFMS, Pereira FEL. Acute liver failure in children: observations in Vitoria, E Santo State, Brazil. Revista da Sociedade Brasileira de Medicina Tropical 35: 483, 2002.

52. Oliveira LHS, Yoshida CFT, Monteiro SS, Câmara FP. Seroepidemiologic survey for hepatitis A and B markers in heath care students from Public University of Rio de Janeiro, Brazil. Revista de Microbiologia de São Paulo 22:226-231, 1991.

53. Pannuti C S, Mendonça JS, Carvalho MJM, Oselka GW, Amato Neto V. Hepatitis antibodies in two socio-economically distinct populations of São Paulo, Brazil. Revista do Instituto de Medicina Tropical de São Paulo 27:162-164, 1985.

54. Paul JR, Havens WP, Sabin AB, Philip CB. Transmission experiments in infectious hepatitis. Journal of American Medical Association 1128:911-915, 1945.

55. Paula VS, Arruda ME, Vitral Cl, Gaspar AMC. Seroprevalence of viral hepatitis in Riverine Communities from the Western Region of the Brazilian Amazon Basin. Memórias do Instituto Oswaldo Cruz 96:1123-1128, 2001.

56. Pavia AT, Nielsen L, Armington L, Thurman DJ, Tierney E, Nichols CR A community-wide outbreak of hepatitis $A$ in a religious 
community: impact of mass administration of immunoglobulin. American Journal of Epidemiology 131:1085-1093,1990.

57. Pinho JRR, Sumita LM, Moreira RC, Souza VAF, Saraceni CP, Oba IT, Carvalho MCS, Pannuti CS. Duality of patterns in hepatitis A epidemiology: a study involving two socioeconomically distinct populations in Campinas, São Paulo State, Brazil. Revista do Instituto de Medicina Tropical de São Paulo 40:105-106, 1998.

58. Provost JJ, Ittensohn OL, Viullarejos VM, Hilleman MR. A specific complement fixation test for human hepatitis $A$ employing $C R$ 326 virus antigen. Diagnosis and epidemiology. Proceedings of the Society of Experimental Biology and Medicine 148:962-968, 1975.

59. Purcell RH, Emerson SU. Animal models of hepatitis $A$ and $E$. Institute of Laboratory Animal Resources (ILAR) Journal 42:161177, 2001.

60. Purcell RH, Wong DC, Moritsugu Y, Dienstag JL, Routenberg JÁ, Boggs JD. A microtiter solid phase radioimmunoassay for hepatitis A antigen and antibody. Journal of Immunology 116:3493561976.

61. Queiróz DAO, Cardoso DDP, Martelli CMT, Martins RMB, Porto SOB, Azevedo MSP, Borges AMT, Daher RR. "Risk factor and prevalence of antibodies against hepatitis A virus (HAV) in children from day-care centers, in Goiania, Brazil. Revista do Instituto de Medicina Tropical de São Paulo 37:427-433, 1995.

62. Queiróz DAO, Cardoso DDP, Martelli CMT, Martins RMB, Porto SOB, Azevedo MSP, Borges AMT, Daher RR. "Soroepidemiologia da infecção pelo vírus da hepatite A em "Meninos de/na Rua" de Goiânia-Goiás". Revista da Sociedade Brasileira de Medicina Tropical 28:199-203, 1995.

63. Ramonet M, da Silveira TR, Lisker-Melman M, Ruttiman R. Pernambuco E, Cervantes Y, Canerto-Velasco MC, FalleirosCarvalho LE, Azevedo T, Targa-ferreira C, Clemens AS. A twodose combined vaccine against hepatitis $A$ and $B$ in healthy children and adolescents compared to the corresponding monovalent vaccines. Archives of Medical Research 33:67-73, 2002.

64. Robertson BH. Viral hepatitis and primates: historical and molecular analysis of human and non-human primate hepatitis A, B and the GB-related viruses. Journal of Viral Hepatitis 8:233242, 2001.

65. Routenberg JA, DienstagJL, Harrison WO, Kilpatrick ME, Hooper RR, Chisari FV, Purcell RH, Fornes MF. Food borne outbreak of hepatitis $A$ : clinical and laboratory features of acute and protracted illness. American Journal of Medical Science 278:1123-1137, 1979.

66. Saback FL, Palmer TE, Sabino RR, Carvalho SM, Amorim LM, Gaspar AM, Oliveira ML, Yoshida CF, Niel C. Infection with hepatitis A and TT viruses and socioeconomic status in Rio de Janeiro, Brazil. Scandinavian Journal of Infectious Diseases 33:121-125, 2001

67. Sacher RA, Peters SM, Bryan JÁ. Testing for viral hepatitis. A practice parameter. American Journal of Clinical Pathology 113:12-17 2000

68. Schiodt FV, Attilasoy E, Obaid-Shakil A, Schiff ER, Caldwell C, Kowdley KV, Stribling R, Crippen JS, Flamm S, Somberg KA, Rosen H, McCshland TM, Hay JE, Lee WM and The Acute Liver Failure Study Group. Etiology and outcome for 295 patients with acute liver failure in the United States. Liver Transplantation Surgery 5: 29-34, 1999
69. Silva LCA. Hepatites Agudas e Crônicas. $2^{a}$ edição, Sarvier, São Paulo, p. 137-142, 1995.

70. Sjögren $\mathrm{MH}$, Hoke $\mathrm{CH}$, Binn LN, Eckels $\mathrm{KH}$, Dubois DR, Lyde L,Tsuchida A, Oaks Jr S, Warchwicki R, Lednar W, Chloupek R, Ticehurst J, Bancroft WH. Immunogenicity of an inactivated hepatitis A vaccine. Annals of Internal Medicine 114: 470$471,1991$.

71. Sjögren MH, TanoH, Fay O, Sileoni S, Cohen BD, Burke DS, Feighny RJ. Hepatitis A virus in stool during clinical relapse. Annals of Internal Medicine 106:221-226, 1987.

72. Stapleton JT, Raina V, Winokur PL, Walters K, Klinzman D, Rosen $\mathrm{E}$, McLinden $\mathrm{JH}$. Antigenic and immunogenic properties of recombinant hepatitis $A$ virus $14 S$ or $70 S$ subviral particles. Journal of Virology 67:1080-1085, 1993.

73. Stokes Jr J, Neefe JR. The prevention and attenuation of infectious hepatitis with gammaglobulin (preliminary note). Journal of the American Medical Association 127:144-145, 1945.

74. Storch GA, Bodicky C, Parker M, Blecka LJ, Aach RD. Use of conventional and IgM specific radioimmunoassay for anti-hepatitis A antibody in an outbreak of hepatitis A. American Journal of Medicine 73:663-668, 1982.

75. Struchiner CJ, Almeida LM, Azevedo RS, Massad E. Hepatitis A incidence rate estimates from a pilot seroprevalence survey in Rio de Janeiro, Brazil. International Journal of Epidemiology 28:776-781, 1999

76. Tong MJ, el-Farra NS, Grew MI. Clinical manifestations of hepatitis A: recent experience in a community teaching hospital. Journal of Infectious Disease 171 (sup1):s15-s18, 1995.

77. Tottsuka A, Moritsugu Y. Hepatitis A proteins. Intervirology 42:6368, 1999.

78. Trinta KS, Liberto MIM, Paula VS, Yoshida CFT, Gaspar AMC. Hepatitis $E$ virus infection in selected Brazilian populations. Memórias do Instituto Oswaldo Cruz 96:25-29, 2001.

79. Valbracht A, Gabriel P, Maiert K, Haratmann F, Steinhardt HJ, Muller C, Wolf A, Manncke KH, Flehmig B. Cell-mediated cytotoxicity in hepatitis A viral infection. Hepatology 6:1308-1314, 1986.

80. Vento S, Garofano T, Renzini C, Cainelli F, Casali F, Ghironzi G, Ferraro T, Concia E. Fulminant hepatitis associated with hepatitis A virus superinfection in patients with chronic hepatitis C. New England Journal of Medicine 338:286-290, 1998.

81. Vitral CL, Yoshida CFT, Lemos ERS, Teixeira CS, Gaspar AMC. Age-specific prevalence of antibodies to hepatitis A in children and adolescents from Rio de Janeiro, Brazil, 1978 and 1995. Relationship of prevalence to environmental factors. Memórias do Instituto Oswaldo Cruz 93:1-5, 1998.

82. Voegt H. Zur aetiologie der hepatitis epidemica. Muenchener Medizinische Wochenschrift 89:76-79 1942.

83. Yoshida CFT, Nogueira RMR, Mercadante LAC, Pinhão AT, Schatzmayr HG. Seroepidemiological survey of hepatitis A and $B$, cytomegalovirus and herpes simplex type 2 in prime blood donors from Rio de Janeiro, Brazil. Revista de Microbiologia de São Paulo 18:5-11, 1987.

84. Yokosuka O. Molecular biology of hepatitis A virus: significance of various substitutions in the hepatitis A virus genome. Journal of Gastroenterology and Hepatology 15 (supl II): 91-97 2000. 